\title{
A Kinetic Method to Identify the Optimum Temperature for $\beta$-glucanase Activity
}

\author{
F. Venturi, G. Andrich,* M.F. Quartacci, C. Sanmartin, L. Andrich and A. Zinnai \\ Dipartimento di Scienze Agrarie, Alimentari e Agro-industriali, University of Pisa, Pisa, Italy
}

Submitted for publication: May 2013

Accepted for publication: July 2013

Key words: $\beta$-glucan, enzymatic hydrolysis, temperature

\begin{abstract}
Enzymatic preparations containing $\beta$-glucanases are largely utilised in winemaking to facilitate the filtration of musts and wines coming from grapes affected by Botrytis cinerea, and to induce the release of mannoproteins and oligosaccharides from the cell wall of yeasts. The aim of the present work was to investigate the effect of temperature on $\beta$-glucanase activity. For this purpose, the kinetic activity of a commercial enzymatic preparation containing $\beta$-glucanases was tested utilising a model solution (buffer solution of $\beta$-glucan extracted from alcoholic yeasts with a $\mathrm{pH}$ similar to a must/wine, with or without $13 \%$ ethanol added) at different temperatures ranging from 20 to $40^{\circ} \mathrm{C}$. By an innovative procedure based on a kinetic model able to describe the time evolution of D-glucose accumulation - the final product of $\beta$-glucan hydrolysis - it was possible to relate the maximum rate of this process to temperature. The temperature at which the enzymatic activity showed the maximum value $\left(T_{\text {max }}\right)$ was close to $30^{\circ} \mathrm{C}$, without any substantial variation following ethanol addition. Indeed, in spite of a remarkable reduction (of about $66 \%$ ) in the catalytic activity shown by the commercial enzymatic preparation, no significant variation of the $T_{\max }$ was observed, suggesting that the presence of an inhibitor such as ethanol in the reaction medium did not change the sensibility of the enzymes to temperature.
\end{abstract}

\section{INTRODUCTION}

Enzymatic preparations containing $\beta$-glucanases find many possible applications in the food industry (Baht, 2000). Microbial exopolysaccharides are gaining importance in the food as well as other industries because of their functional properties, and therefore are used to improve the rheology of foods. However, the possible utilisation of these polymeric compounds are often strongly limited by their low water solubility. Fragmentation of $\beta$-glucan promoted by hydrolytic enzymes (i.e. $\beta$-glucanases) can enhance water solubility by reducing the degree of polimerisation. These polysaccharides are widely diffused in nature and can be found in some algae, fungi and yeasts, and are also present in crops such as barley and oats. The $\beta$-D-glucans are constituted by a main chain formed by $\beta$-D-glucose units joined together by $\beta-1,3$ (yeasts and fungi such as Saccharomyces cerevisiae, S. bayanus and Botrytis cinerea) or $\beta-1,4$ (cereals) glucosidic bonds, and by a variable number of lateral chains with different lengths that are linked to the main chain by $\beta-1,6$ or $\beta-1,2$ bonds. In this way it is possible to obtain a large number of different $\beta$-glucans with different physicochemical properties and, in particular, different water solubility values (Dubourdieu et al., 1981; Villetaz et al., 1984).

$\beta$-Glucanases represent a broad class of enzymes, which includes both exo/endo forms of $\beta(1,6)$-glucanases that are able to promote the hydrolysis of $\beta(1,6)-O$-glycosidic bonds, connecting lateral branches with the main polymeric chain of $\beta$-glucans, as well as exo- $\beta(1,3)$ and endo- $\beta(1,3)$ glucanases, which promote the lysis of terminal and internal $\beta(1,3)$-bonds respectively. Commercial preparations of these enzymes are utilised extensively in the brewing industry and in winemaking to facilitate the filtration of musts and wines, particularly those coming from grapes affected by $B$. cinerea. The presence in musts and wines of a reduced amount of $\beta$-Dglucans ( 5 to $15 \mathrm{mg} / \mathrm{L}$ ) prevents the natural sedimentation of cloud particles (Dubourdieu et al., 1981; Villettaz et al., 1984) and induces filter stoppages (Goffard et al., 2004). $\beta$-Glucanase preparations are also employed at the end of the alcoholic fermentation to promote the lysis of the yeast cell walls, followed by the release into the wine of their main constituents, including mannoproteins and oligomeric fragments of $\beta$-glucans (Parodi, 2002; Morata et al., 2003; Comuzzo et al., 2005; Palomero et al., 2007). In order to induce a significant extraction of these latter compounds, the finished wines must be maintained in contact with the dregs of fermentation for long times (six to 12 months) and stirred frequently (batônnage). To reduce these long periods, the related high costs and the risk of a loss of quality due to the possible formation of undesired flavours (reduced volatile substances formed in low oxidative conditions), commercial

*Corresponding author: E-mail: gandrich@agr.unipi.it

Aknowledgements: The GC-MS facilities of the Food Quality Certification Unit of the University of Ioannina were used for this work 
preparations rich in $\beta$-glucanases can be utilised. Moreover, the identification of the optimum temperature able to induce high kinetic activities could provide further technological and economic advantages.

Information concerning optimal $\mathrm{pH}$ and temperature values has been reported for exo/endo $\beta$ - $(1,3)$-glucanases (Sun et al., 2006; Wang et al., 2007; Vijayendra et al., 2008; Kumagai \& Takao, 2009; Ng et al., 2009; Blättel et al., 2011), $\beta$-(1,6)(1,4)-glucanases (Srivastava et al., 1993; De la Cruz et al., 1995), and also for enzymatic preparations containing a mixture of $\beta$-glucanases (Palomero et al., 2007; Doughari, 2011). These enzymatic preparations were isolated from different sources like fungi (Aspergillus spp., Stachybotrys elegans, Rhizoctonia solani, Rhizopus microsporus, Trichoderma harzianum, T. koningii, Pennicillium oxalicum, P. citrinum, Botrytis cinerea, Chaetomium spp.), bacteria (Delftia tsuruhatensis, Rumunicoccus spp., Geobacillus spp.) and oenological yeasts. The heterogeneous sources used to isolate the different $\beta$-glucanes account for the differences occurring in the enzymes, and justify the broad range (30 to $100^{\circ} \mathrm{C}$ ) of optimal temperature reported in the literature (Srivastava et al., 1993; De la Cruz et al., 1995; Celestino et al., 2006; Palomero et al., 2007; Kumagai \& Takao, 2009; $\mathrm{Ng}$ et al., 2009; Blättel et al., 2011; Doughari, 2011).

To experimentally identify the optimal temperature of individual $\beta$-glucanases or enzymatic preparations, a linear $\beta$-glucan (laminarim) produced by brown algae has often been utilised as substrate, although different forms of this polysaccharide, such as pustulan $(\beta(1,6)$ polysaccharide) or $\beta$-glucans extracted from barley, $B$. cinerea and alcoholic yeasts ( $S$. cerevisiae), have also been used. The accumulation over time of reducing sugars originating from the hydrolysis of these substrates was often used to determine the evolution of the enzymatic activity as a function of temperature or $\mathrm{pH}$ adopted, while in some cases it was the increase over time of D-glucose - the final product of the hydrolytic process - that was used to represent the kinetic parameter followed.

Due to the broad ranges of optimal $\mathrm{pH}$ and temperature reported in the literature, it is not easy to get useful information that can be applied to industrial processes, and to winemaking in particular. As the $\mathrm{pH}$ does not change significantly in a must/wine (3.2 to 3.4), temperature represents the main operating parameter that can be modified usefully. The molecular complexity of $\beta$-glucan is a function of the biological substrate from which it is derived: while $\beta$-glucan extracted from cereals is linear, with $\beta(1-3 / 1$ 4 ) bonds resembling the ones present in bacteria, where $\beta(1-3)$ bonds are largely predominant, the polysaccharides extracted from fungi (B. cinerea) and alcoholic yeasts are more complex. These are formed by a main polymeric fraction of D-glucose units connected by $\beta(1-3)$ bonds to which numerous ramifications of short (fungi) or long (yeasts) polymeric chains are linked by $\beta(1-6)$ and $\beta(1-2)$ bonds. Thus, in order to promote the hydrolysis of these latter forms of $\beta$-glucan present in musts/wines, a mixture of $\beta$-glucanases (endo/exo $\beta(1,3)$-glucanases, endo/exo $\beta(1,2)$-glucanases and endo/exo $\beta(1,6)$-glucanases) should be used. Moreover, to detect the effect of temperature on this hydrolytic process, the time accumulation of D-glucose should be followed to highlight the possible inactivation of the most sensible forms of $\beta$-glucanase (Villettaz et al., 1984; Humbert-Goffard et al., 2004; Zinnai et al., 2010).

As many components of wine, such as ethanol (Zinnai et al., 2010) and phenols, may act as enzymatic inhibitors (Villettaz et al., 1984; Humbert-Goffard et al., 2004), the kinetic activity of a commercial enzymatic preparation containing a mixture of $\beta$-glucanases was tested at different temperatures using a model solution consisting of $\beta$-glucan extracted from yeasts and dissolved in a buffer to obtain a $\mathrm{pH}$ value similar to that of must/wine $(\mathrm{pH}=3.3)$. To evaluate whether the addition of an inhibitor could sensibly modify the temperature connected with optimum $\beta$-glucanase activities, $13 \%$ ethanol was added to the same buffer solution to simulate a wine.

The hydrolytic activity shown by the tested enzymatic preparation was evaluated following the accumulation in the reaction medium of the end product, namely D-glucose. The utilisation of the proposed model solution allowed to exclude any possible undesired interference due to the utilisation of a complex medium such as wine.

\section{MATERIALS AND METHODS}

Due to the high number and chemical complexity of compounds (oligosaccharides characterised by different molecular structure and weight) that could potentially be obtained by the lysis of $\beta$-glucan polysaccharides (Dubourdieu et al., 1981; Humbert-Goffard et al., 2004), the enzymatic activity was monitored following D-glucose accumulation.

A granular preparation, Vinoflow G (Laffort Oenologie), containing pectinases and $\beta$-glucanases isolated from microbial strains of Aspergillus niger and Trichoderma harzianum, was used. This additive is classified "food grade" since it contains no mycotoxins, the concentrations of metals are lower than $30 \mu \mathrm{g} / \mathrm{L}$, those of $\mathrm{Pb}$ and As are lower than 5 and $3 \mu \mathrm{g} / \mathrm{L}$ respectively, and no antibiotic activity is present. Vinoflow $G$ is particularly active in promoting the degradation of pectic substances and the hydrolysis of $\beta$-glucans, thus it can be employed usefully during wine stabilisation to increase the filterability of wine, thereby reducing the possible need to add other clarifiers. Moreover, the utilisation of this preparation is recommended at concentrations of $\mathrm{SO}_{2}$ dissolved in wine that are lower than $500 \mathrm{mg} / \mathrm{L}$ and at temperatures higher than $12^{\circ} \mathrm{C}$ (Parodi, 2002).

The $\beta$-glucan used as enzymatic substrate was isolated from alcoholic yeasts ( $S$. cerevisiae), and presents a high degree of polymerisation and a relevant number of lateral branches (Sigma, product No. G5011).

In a $200 \mathrm{~mL}$ glass vessel, $10 \mathrm{~mL}$ of a Vinoflow $\mathrm{G}$ solution containing $50 \mathrm{mg}$ of enzymatic preparation dissolved in $1 \mathrm{~L}$ of citrate buffer were added to $90 \mathrm{~mL}$ of a $\beta$-glucan solution (500 mg of $\beta$-glucan in $1 \mathrm{~L}$ of citrate buffer). The buffer was prepared by adding $448 \mathrm{~mL}$ of a solution containing $105.05 \mathrm{~g}$ of citric acid in $1 \mathrm{~L}$ of $1 \mathrm{~N} \mathrm{NaOH}$ to $552 \mathrm{~mL}$ of $0.1 \mathrm{~N} \mathrm{HCl}$. The model solution, which had a $\mathrm{pH}$ value (3.3) similar to that of must/wine, contained $5 \mathrm{~g} / \mathrm{hL}$ of Vinoflow $\mathrm{G}$ and $45 \mathrm{~g} / \mathrm{hL}$ of $\beta$-glucan. The same procedure was followed to prepare the solution with an ethanol concentration similar to wine. In this case, instead of de-ionised water, a hydro- 
alcoholic solution containing $13 \%(\mathrm{v} / \mathrm{v})$ ethanol was used for the preparation of the citrate buffer.

To prevent any microbial contamination that could affect D-glucose accumulation over time, the glass vessel was previously sterilised by a suitable heat treatment (autoclaved), while the sterility of the two solutions used (Vinoflow $G$ and $\beta$-glucan) was ensured by filtration $(0.22 \mu \mathrm{m}$ pore size). Moreover, to avoid any undesired oxidation from occurring, the experimental runs were carried out while maintaining the glass vessel under an inert atmosphere of $\mathrm{N}_{2}$ previously sterilised by filtration, while the selected temperatures $\left(20,25,30,35\right.$ and $\left.40^{\circ} \mathrm{C}\right)$ were ensured by a thermostatic bath. The addition of the Vinoflow $\mathrm{G}$ solution $(10 \mathrm{~mL})$ to $\beta$-glucan $(90 \mathrm{~mL})$ represented the initial time of the kinetic run $(\mathrm{t}=0)$. A standard experimental run lasted more than one week.

The amount of D-glucose accumulated in the reaction media was evaluated using commercial enzymatic kits (Diffchamb, Megazyme). The identification of the best values to be assigned to the functional parameters of the mathematical equation used to relate the evolution of the experimental data over time was done with a commercial statistical program (Buzzi Ferraris \& Manca, 1996). This program identifies, in a space of $\mathrm{j}$-dimensions (where $\mathrm{j}$ represents the number of equation parameters), the minimum value of the F function, which is obtained from the sum of the squares of differences occurring between calculated $\left(\mathrm{R}_{\text {calc.,i }}^{*}\right)$ and experimental $\left(\mathrm{R}_{\text {exper, } \mathrm{i}}^{*}\right)$ values:

$\mathrm{F}=\sum_{\mathrm{i}=1}^{\mathrm{N}}\left(\mathrm{R}_{\text {calc., } \mathrm{i}}^{*}-\mathrm{R}_{\text {exper., } \mathrm{i}}\right)^{2}$

where $\mathrm{i}=\mathrm{i}$-calculated/experimental value, and $\mathrm{N}=$ total number of experimental values.

\section{RESULTS AND DISCUSSION}

The enzymatic activities shown by $\beta$-glucanases as a function of the selected temperatures were determined following the accumulation of D-glucose over time. To evaluate the highest rate of D-glucose accumulation, a previously developed kinetic model (Zinnai et al., 2010) was used to avoid approximated or graphical identifications associated with high levels of inaccuracy (Villettaz et al., 1984; HumbertGoffard et al., 2004). Indeed, small graphical deviations might induce high differences in the value assumed by the slope of the straight line, hence the maximum rates obtained could be affected by high levels of error. Moreover, the determination of which experimental points should be utilised to clearly identify the linear fraction of the curve related to D-glucose accumulation with time is not always easy. The utilisation of a mathematical function that is able to correlate the experimental points with the calculated ones may allow the unequivocal identification of the maximum reaction rate, namely a parameter related to the optimal temperature.

Figure 1 shows the evolution over time of the experimental and calculated points related to D-glucose accumulation for a generic enzymatic run $\left(\mathrm{T}=35^{\circ} \mathrm{C}\right)$. To allow an easier and immediate comparison between experimental runs carried out at different temperatures, the kinetic model already reported in a previous paper was used (Zinnai et al., 2010).

According to this kinetic approach, if the rate ofD-glucose production $\left(\mathrm{d}[\mathrm{Glu}]_{\mathrm{t}=\mathrm{t}} / \mathrm{dt}\right)$ is hypothesised to be proportional to the difference between the maximum concentration of D-glucose, which potentially could be obtained when the hydrolysis time tends to infinite $\left([\mathrm{Glu}]_{\mathrm{t}=\mathrm{t}} / \mathrm{dt}\right)$ and that $\left([\mathrm{Glu}]_{\mathrm{t}=t}\right)$ actually present in the reaction medium at a generic time $(\mathrm{t}=\mathrm{t})$, the following expression can be obtained:

$\mathrm{d}[\mathrm{Glu}]_{\mathrm{t}=\mathrm{t}} / \mathrm{dt}=\mathrm{k}\left([\mathrm{Glu}]_{\mathrm{t}=\infty}-[\mathrm{Glu}]_{\mathrm{t}=-\mathrm{t}}\right)$

where $\mathrm{k}$ represents the kinetic constant related to D-glucose accumulation. This differential equation can be integrated to obtain a kinetic relation that describes the evolution over

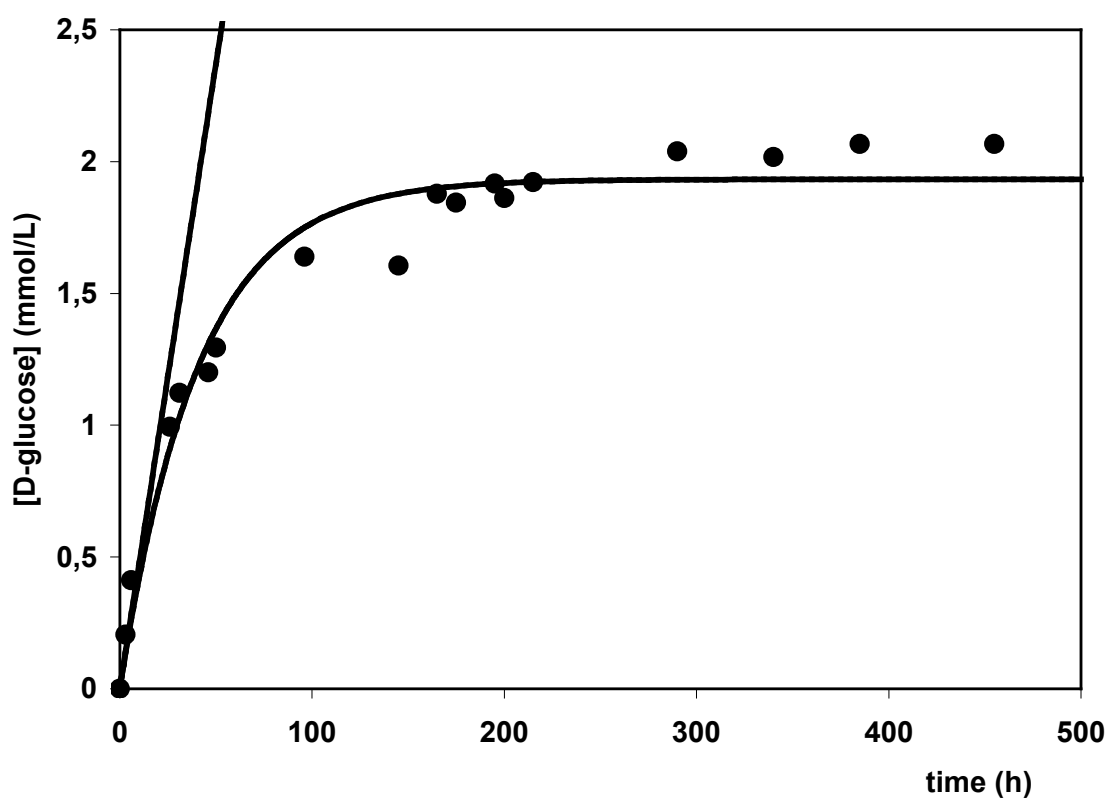

FIGURE 1

Evolution of experimental and calculated points related to D-glucose produced by the hydrolysis of $\beta$-glucan representative of a generic enzymatic run $\left(\mathrm{T}=35^{\circ} \mathrm{C}, \mathrm{r} 2=0.97\right)$, and tangent to the curve at the initial point $(\mathrm{t}=0)$. 
time of the D-glucose concentration in the reaction medium (Fig. 1):

$[\mathrm{Glu}]_{\mathrm{t}=\mathrm{t}}=[\mathrm{Glu}]_{\mathrm{t}=\infty}\left(1-\mathrm{e}^{-\mathrm{kt}}\right)$

The two functional parameters $\mathrm{k}$ and $[\mathrm{Glu}]_{\mathrm{t}=\infty}$ were assumed to be valid measures of the kinetic effect induced on $\beta$-glucanase activities by the different reaction temperatures.

To determine the maximum reaction rate, the first derivative $\left(\mathrm{d}[\mathrm{Glu}]_{\mathrm{t}=\mathrm{t}} / \mathrm{dt}\right)$ of equation (3) can be calculated:

$\mathrm{d}[\mathrm{Glu}]_{\mathrm{t}=\mathrm{t}} / \mathrm{dt}=\mathrm{d}\left([\mathrm{Glu}]_{\mathrm{t}=\infty}\left(1-\mathrm{e}^{-\mathrm{kt}}\right)\right) / \mathrm{dt}=[\mathrm{Glu}]_{\mathrm{t}=\infty} \mathrm{k} \mathrm{e}^{-\mathrm{kt}}=[\mathrm{Glu}]_{\mathrm{t}=\infty} \mathrm{k} / \mathrm{e}^{\mathrm{kt}}$

and the mathematical relation between the rate of D-glucose accumulation and the reaction time can be obtained. This expression reaches its maximum value at the initial run time $(\mathrm{t}=0)$ :

$\lim _{\mathrm{t} \rightarrow 0}\left(\mathrm{~d}[\mathrm{Glu}]_{\mathrm{t}-\mathrm{t}} / \mathrm{dt}\right)=\lim _{\mathrm{t} \rightarrow 0}\left([\mathrm{Glu}]_{\mathrm{t}=\infty} \mathrm{k} \mathrm{e}^{-\mathrm{kt}}\right)=[\mathrm{Glu}]_{\mathrm{t}=\infty} \mathrm{k}$

where the maximum reaction rate is equal to the product of the two functional parameters $\mathrm{k}$ and $[\mathrm{Glu}]_{t=\infty}$ used to describe the evolution over time of D-glucose accumulation. This product represents the slope of the tangent to the initial point $\left(r_{(t=0)}\right)$ of the curve describing D-glucose accumulation in the reaction medium (Fig. 1).

To identify the best values to be assigned to the functional parameters ( $\mathrm{k}$ and $[\mathrm{Glu}]_{\mathrm{t}=\infty}$ ) involved in kinetic equation (3), the statistical program Burenl was utilised (Buzzi Ferraris \& Manca, 1996). The high values assumed by the squares of the correlation coefficients calculated for the linearised form of the kinetic equation in the Taylor series (Table 1) provide an indication of the suitability of the theoretical approach followed and of the reliability of the related kinetic equations obtained.

The same experimental approach was also adopted to determine the activities of $\beta$-glucanases at the selected temperatures following the addition of the commercial preparation to the model solution containing $13 \%(\mathrm{v} / \mathrm{v})$ ethanol. Table 2 reports the values of the two parameters related to the exponential equation introduced to describe the accumulation over time of D-glucose.
As the $r_{(t=0)}$ values show a parabolic trend with increasing temperatures, with a maximum located within the tested temperatures (Tables 1 and 2), the following mathematical equation was introduced:

$\mathrm{r}_{(\mathrm{t}=0)}=\mathrm{a} \mathrm{T}^{2}+\mathrm{b} \mathrm{T}+\mathrm{c}$

The functional parameters $(\mathrm{a}, \mathrm{b}, \mathrm{c})$ of the parabolic curves that minimise the squares of differences between the calculated and experimental values (Table 3, Fig. 2) were identified using the statistical program Burenl (Buzzi Ferraris \& Manca, 1996). The highest enzymatic activities over temperature of these two curves can easily be determined by referring to the coordinates of the points where their first derivatives are equal to zero:

$\mathrm{r}_{(\mathrm{t}=0)}^{\prime}=2 \mathrm{a} \mathrm{T}_{\max }+\mathrm{b}=0$

so that $\mathrm{T}_{\max }=-\mathrm{b} /(2 \mathrm{a})=-7.78 \cdot 10^{-5} /\left(-2 \cdot 12.98 \cdot 10^{-8}\right)=299.7$ $\mathrm{K}=26.5^{\circ} \mathrm{C}$ for the model solution simulating a must, and $\mathrm{T}_{\text {max }}=303.8 \mathrm{~K}=30.7^{\circ} \mathrm{C}$ for the enzymatic preparation dissolved in the hydro-alcoholic solution simulating a wine.

As shown by the confidence intervals (Table 3 ), the functional parameters $(a, b)$ used to determine the $T_{\max }$ values are affected by high variability, so that the optimal temperature identified for the model solution simulating a must $\left(26.5^{\circ} \mathrm{C}\right)$ is statistically equivalent to that simulating a wine $\left(30.7^{\circ} \mathrm{C}\right)$. Furthermore, these values are close to the lower limit of the range $\left(30\right.$ to $\left.100^{\circ} \mathrm{C}\right)$ of optimal temperatures reported in the literature for the activities of the enzymatic preparations containing $\beta$-glucanases. The utilisation of a preparation containing several protein forms that are catalytically active and characterised by different sensitivities to temperature might partially explain the high sensitivity to temperature observed during the experimental work. According to Humbert-Goffard et al. (2004), who used an analogous commercial enzymatic preparation with a similar $\mathrm{pH}(\mathrm{pH}=3.4)$ and detected D-glucose accumulation deriving from the hydrolysis of laminarim (a linear $\beta(1,3)$ glucan produced by Laminaria digitata), the optimum temperature is located close to $50^{\circ} \mathrm{C}$. This difference might

\section{TABLE 1}

Values assumed as a function of temperature by the two functional parameters, $\mathrm{k}$ and $[\mathrm{Glu}]_{\mathrm{t}=\infty}$, involved in the kinetic equation used to describe the accumulation over time of D-glucose in the model solution simulating a must, square of correlation coefficients $\left(\mathrm{r}^{2}\right)$ calculated for the linearised form in Taylor series, and corresponding values of the initial reaction rates $\left(\mathrm{r}_{(\mathrm{t}=0)}\right)$.

\begin{tabular}{llcccc}
\hline Run & $\begin{array}{c}\text { Temperature } \\
\left(\mathrm{K} /{ }^{\circ} \mathrm{C}\right)\end{array}$ & $\begin{array}{c}\mathrm{k} \cdot 10^{6} \\
\left(\mathrm{~s}^{-1}\right)\end{array}$ & $\begin{array}{c}{[\mathrm{Glu}]_{\mathrm{t}-\infty}} \\
\left(\mathrm{mmol} \cdot \mathrm{l}^{-1}\right)\end{array}$ & $\mathrm{r}^{2}$ & $\begin{array}{c}\mathrm{r}_{(\mathrm{t}=0)}=\left(\mathrm{k} \cdot[\mathrm{Glu}]_{\mathrm{t}=\infty}\right) \cdot 10^{6} \\
\left(\mathrm{mmol}^{-1} \cdot \mathrm{s}^{-1}\right)\end{array}$ \\
\hline $1 \mathrm{a}^{*}$ & $293.15 / 20$ & $5.71 \pm 0.21$ & $3.6 \pm 0.5$ & 0.99 & 20.6 \\
$1 \mathrm{~b}$ & $293.15 / 20$ & $4.92 \pm 0.23$ & $3.9 \pm 0.7$ & 0.99 & 19.2 \\
2 & $298.15 / 25$ & $6.82 \pm 0.45$ & $3.3 \pm 0.5$ & 0.99 & 22.5 \\
$3 \mathrm{a}$ & $303.15 / 30$ & $11.41 \pm 0.50$ & $2.8 \pm 0.4$ & 0.99 & 31.9 \\
$3 \mathrm{~b}$ & $303.15 / 30$ & $12.80 \pm 0.72$ & $2.0 \pm 0.3$ & 0.97 & 26.0 \\
$4 \mathrm{a}$ & $308.15 / 35$ & $5.71 \pm 0.21$ & $1.9 \pm 0.2$ & 0.97 & 11.0 \\
$4 \mathrm{~b}$ & $308.15 / 35$ & $5.88 \pm 0.27$ & $2.7 \pm 0.3$ & 0.97 & 15.7 \\
$5 \mathrm{a}$ & $313.15 / 40$ & $5.56 \pm 1.19$ & $0.8 \pm 0.4$ & 0.93 & 4.4 \\
$5 \mathrm{~b}$ & $313.15 / 40$ & $4.89 \pm 0.81$ & $1.1 \pm 0.5$ & 0.97 & 5.2 \\
\hline
\end{tabular}

Data are expressed as means \pm confidence intervals $(\mathrm{p}=0.05)$. Experimental runs marked by the same number but different letters represent replications carried out at the same temperature. $\mathrm{k}$, kinetic constant related to D-glucose accumulation; $[\mathrm{Glu}]_{\mathrm{t}=\infty}$, maximum concentration of D-glucose that could potentially be obtained when the hydrolysis time tends to infinite. 
TABLE 2

Values assumed as a function of temperature by the two functional parameters, $\mathrm{k}$ and $[\mathrm{Glu}]_{\mathrm{t}=\infty}$, involved in the kinetic equation used to describe the accumulation over time of D-glucose in the model solution added with $13 \%$ (v/v) ethanol to simulate a wine, square of correlation coefficients $\left(\mathrm{r}^{2}\right)$ calculated for the linearised form in Taylor series, and corresponding values of the initial reaction rate $\left(\mathrm{r}_{(\mathrm{t}=0)}\right)$.

\begin{tabular}{lccccc}
\hline Run & $\begin{array}{c}\text { Temperature } \\
\left(\mathrm{K} /{ }^{\circ} \mathrm{C}\right)\end{array}$ & $\begin{array}{c}\mathrm{k} \cdot 10^{6} \\
\left(\mathrm{~s}^{-1}\right)\end{array}$ & $\begin{array}{c}{[\mathrm{Glu}]_{\mathrm{t}=\infty}} \\
\left(\mathrm{mmol} \cdot \mathrm{l}^{-1}\right)\end{array}$ & $\mathrm{r}^{2}$ & $\begin{array}{c}\mathrm{r}_{(\mathrm{t}=0)}=\left(\mathrm{k} \cdot[\mathrm{Glu}]_{\mathrm{t}=\infty}\right) \cdot 10^{6} \\
\left(\mathrm{mmol} \cdot \mathrm{l}^{-1} \cdot \mathrm{s}^{-1}\right)\end{array}$ \\
\hline 1 & $293.15 / 20$ & $3.89 \pm 0.83$ & $1.52 \pm 0.07$ & 0.69 & 5.91 \\
$2 \mathrm{a} *$ & $298.15 / 25$ & $3.06 \pm 0.28$ & $1.54 \pm 0.05$ & 0.96 & 4.71 \\
$2 \mathrm{~b}$ & $298.15 / 25$ & $3.33 \pm 0.28$ & $1.56 \pm 0.03$ & 0.98 & 5.19 \\
3 & $303.15 / 30$ & $4.72 \pm 1.11$ & $2.09 \pm 0.04$ & 0.66 & 9.87 \\
$4 \mathrm{a}$ & $308.15 / 35$ & $6.39 \pm 0.28$ & $1.18 \pm 0.05$ & 0.96 & 7.54 \\
$4 \mathrm{~b}$ & $308.15 / 35$ & $6.67 \pm 0.27$ & $1.61 \pm 0.03$ & 0.96 & 10.73 \\
5 & $313.15 / 40$ & $4.44 \pm 0.55$ & $0.73 \pm 0.07$ & 0.67 & 3.24 \\
\hline
\end{tabular}

Data are expressed as means \pm confidence intervals $(\mathrm{p}=0.05)$. ${ }^{*}$ Experimental runs marked by the same number but different letters represent replications carried out at the same temperature. $\mathrm{k}$, kinetic constant related to D-glucose accumulation; $[\mathrm{Glu}]_{\mathrm{t}=\infty}$, maximum concentration of D-glucose that could potentially be obtained when the hydrolysis time tends to infinite.

\section{TABLE 3}

Values assumed by the functional parameters $(a, b, c)$ of the curve able to minimise the squares of differences between calculated and experimental values of the initial reaction rate $\left(\mathrm{r}_{(\mathrm{t}=0)}\right)$ over temperature when the enzymatic commercial preparation was added to a model solution simulating must or wine, and square of the correlation coefficients $\left(\mathrm{r}^{2}\right)$ calculated for the linearized form in Taylor series.

\begin{tabular}{|c|c|c|c|c|}
\hline Model solution simulating a & $-a \cdot 10^{8}$ & $\mathrm{~b} \cdot 10^{5}$ & $-c \cdot 10^{3}$ & $r^{2}$ \\
\hline must (citrate buffer, $\mathrm{pH}=3.3$ ) & $12.98 \pm 10.24$ & $7.78 \pm 7.07$ & $11.65 \pm 9.53$ & 0.70 \\
\hline wine (citrate buffer, $\mathrm{pH}=3.3+13 \%(\mathrm{v} / \mathrm{v})$ ethanol) & $4.18 \pm 4.35$ & $2.54 \pm 1.96$ & $3.85 \pm 8.43$ & 0.64 \\
\hline
\end{tabular}

Data are expressed as means \pm confidence intervals $(\mathrm{p}=0.05)$.

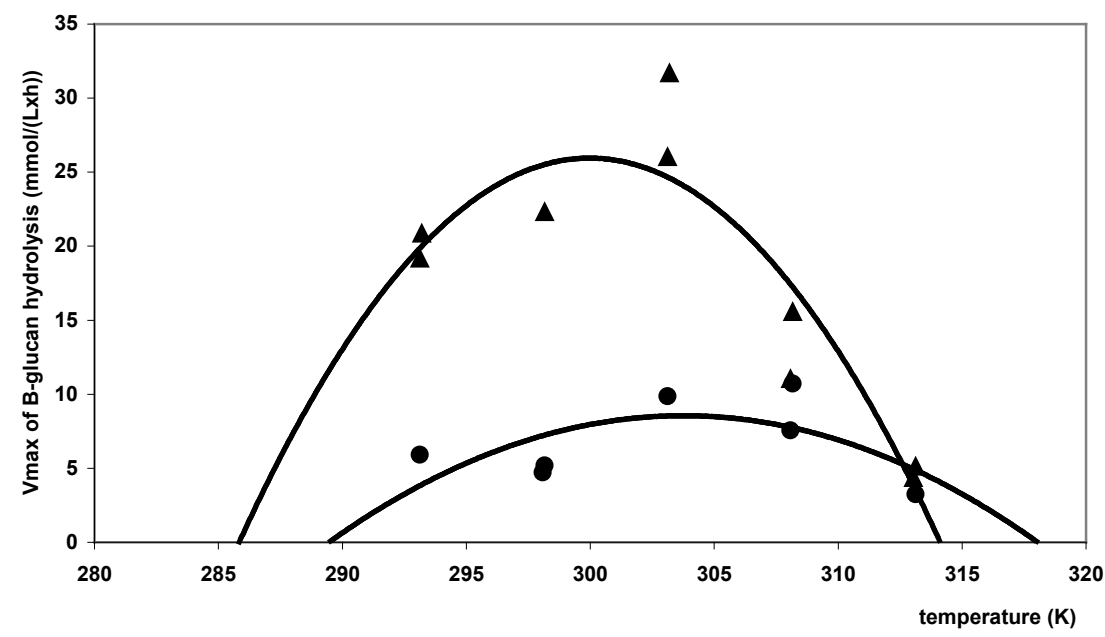

FIGURE 2

Evolution of the maximum D-glucose accumulation rate ( $\operatorname{rmax}=$ tangent to the curve related to D-glucose accumulation at the initial time $(t=0)$ ) when the enzymatic commercial preparation containing $\beta$-glucanases was added to a model solution simulating must (citrate buffer solution, $\mathrm{pH}=3.3$ ) or wine (same model solution added with $13 \%(\mathrm{v} / \mathrm{v})$ ethanol).

essentially be due to the different forms of $\beta$-glucan used as substrate. Indeed, to produce D-glucose by the hydrolysis of linear $\beta(1,3)$-glucan, only the enzymatic activities of endo/ exo $\beta(1,3)$-glucanases are needed, while to hydrolyse the more complex forms of $\beta$-glucan synthesised by alcoholic yeasts, the whole mixture of $\beta(1,3), \beta(1,2)$ and $\beta(1,6)-\beta$ glucanases should participate. In agreement with HumbertGoffard et al. (2004), many authors (Erfle et al., 1988;
Erfle \& Teather, 1991; Monteiro \& Ulhoa, 2006; De Marco \& Felix, 2007; Kumagai \& Takao, 2009; Blättel et al., 2011) have identified the optimal temperature for $\beta(1,3)$ glucanases as close to $50^{\circ} \mathrm{C}$, but it would be sufficient that $\beta(1,6)$-glucanases have their maximum activity at a lower temperature to fully justify the difference in temperature found in this study. 


\section{CONCLUSIONS}

The optimal temperatures found $\left(26.5\right.$ and $30.7^{\circ} \mathrm{C}$ for model solutions simulating a must and a wine respectively) do not differ much from those generally adopted during winemaking, when enzymatic commercial preparations are added to the must to promote the hydrolysis of $\beta$-glucans coming from grapes affected by $B$. cinerea, or to wine left on lees to induce the release of mannoproteins and oligosaccharides from the cell wall of yeasts.

The inhibitory effect induced by ethanol on the accumulation rate of D-glucose $\left(\mathrm{r}_{(\mathrm{t}=0)}\right)$, already reported in a previous paper by Zinnai et al. (2010), is clear. Indeed, the ratio between $r_{(t=0)}$ at $T_{\max }$ in the presence or not of ethanol $\left(r_{(t=0), T \max ,+\mathrm{EtOH} /} \mathrm{r}_{(\mathrm{t}=0), \operatorname{Tmax}}=8.5 \cdot 10^{-6} / 25.9 \cdot 10^{-6}=0.33\right)$ indicates that the addition of ethyl alcohol induced the loss of about $66 \%$ of the catalytic activity. In spite of this remarkable reduction, no significant variation was observed in the $\mathrm{T}_{\max }$ suggesting that the presence of the inhibitor in the reaction medium did not alter the sensitivity to temperature shown by the enzymatic preparation. Thus, it can be suggested that the presence in a wine of other compounds (phenols) that are able to inhibit the enzymatic activity of $\beta$-glucanases (Villettaz et al., 1984; Humbert-Goffard et al., 2004) should not induce a significant change in the temperature at which the maximum catalytic activity occurs.

\section{LITERATURE CITED}

Baht, M.K., 2000. Cellulases and related enzymes in biotechnology. Biotechnol. Adv. 18, 355-383.

Blättel, V., Larisika, M., Pfeiffer, P., Nowak, C., Eich, J. \& König, H., 2011. $\beta$-1,3-glucanase from Delftia tsuruhatensis strain MV01 and its potential application in vinification. Appl. Environ. Microbiol. 77, 983-990.

Buzzi Ferraris, G. \& Manca, D., 1996. BURENL. Politecnico, Dipartimento di Ingegneria Chimica “G. Natta”, Milan.

Celestino, K.R.S., Cunha, R.B. Felix, C.R., 2006. Characterization of a $\beta$-glucanase produced by Rhizopus microsporus var. microsporus, and its potential for application in the brewing industry. BMC Biochemistry 7, 23.

Comuzzo, P., Battistutta, F. \& Tasso, A., 2005. Effet d'un lysat industriel de lévure sur l'évolution des vins rouges en bouteille. J. Int. Sci. Vigne Vin 39, 83-90.

De la Cruz, J., Pintor-Toro, J.A., Benitez, T. \& Llobell, A., 1995. Purification and characterization of an endo- $\beta$-1,6-glucanase from Trichoderma harzianum that is related to its mycoparasitism. J. Bacteriol. 177, 18641871 .

De Marco, J.L. \& Felix, C.R., 2007. Purification and characterization of a $\beta$-1,3-glucanase produced by Trichoderma harzianum showing biocontrol potential. Braz. Arch. Biol Technol. 50, 21-29.

Doughari, J.H., 2011. Production of $\beta$-glucanase enzyme from Pennicillium oxalicum and Pennicillium citrinum. Afr. J. Biotechnol. 10, 9657-9660.

Dubourdieu, D., Ribereau-Gayon, P. \& Fournet, B., 1981. Structure of exocellular $\beta$-D-glucan from Botrytis cinerea. Carbohyd. Res. 93, 294-299.

Erfle, J.D. \& Teather, R.M., 1991. Isolation and properties of a $\beta-1,3-$ glucanase from Ruminococcus flavefaciens. Appl. Environ. Microbiol. 57, 122-129.
Erfle, J.D., Teather, R.M., Wood, P.J. \& Irvin, J.E., 1988. Purification and properties of a $\beta$-1,3-1,4-glucanase (lichenase, 1,3-1,4- $\beta$-D-glucan 4-glucanohydrolase, EC 3.2.1.73) from Bacteroides succinogenes cloned in Escherichia coli. Biochem. J. 255, 833-841.

Goffard, A.H., Saucier, C., Moine-Ledoux, V., Canal-Llaubères, R.M., Dubourdieu, D. \& Glories, Y., 2004. An assay for glucanase activity in wine. Enz. Microb. Tech. 34, 537-543.

Hrmova, M. \& Fincher, G.B., 1993. Purification and properties of three (1-3)- $\beta$-D-glucanase isoenzymes from young leaves of barley (Hordeum vulgare). Biochem. J. 289, 453-461.

Humbert-Goffard, A.H, Saucier, C., Moine-Ledoux, V., Canal-Llaubérres, R.M., Dubourdieu, D. \& Glories Y., 2004. An assay for glucanase activity in wine. Enz. Microb. Tech. 34, 537-543.

Kumagai, Y. \& Takao, O., 2009. Enzymatic properties and the primary structure of a $\beta$-1,3-glucanase from the digestive fluid of the Pacific abalone Haliotis discus hannai. Comp. Biochem. Physiol. B Biochem. Mol. Biol. 154, 113-120.

Monteiro, V.N. \& Ulhoa, C.J., 2006. Biochemical characterization of a $\beta$-1,3-glucanase from Trichoderma koningii induced by cell wall of Rhizoctonia solani. Curr. Microbiol. 52, 92-96.

Morata, A., Gomez-Cordovéz, M.C., Suberviola, J., Bartolomé, B., Colomo, B. \& Suarez, J.A., 2003. Adsorption of anthocyanins by yeast cell walls during the fermentation of red wines. J. Agr. Food Chem. 51, 4084-4088.

Ng, I.S., Li, C.W., Yeh, Y.F., Chen, P.T., Chir, J.L., Ma, C.H., Yu, S.M., Ho, T.H. \& Tong, G.C., 2009. A novel endo-glucanase from the thermophilic bacterium Geobacillus sp. 70PC53 with high activity and stability over a broad range of temperatures. Extremophiles 13, 425-435.

Palomero F., Morata, A., Benito, S., Gonzales, M.C. \& Suarez-Lepe, J.A., 2007. Conventional and enzyme-assisted autolysis during ageing over lees in red wines: Influence on the release of polysaccharides from yeast cell walls and on wine nonnumeric anthocyanin content. Food Chem. 105, 838846.

Parodi, G., 2002. L'affinamento dei vini con l'ausilio di preparati enzimatici. Vignevini 5, 54-58.

Srivastava, S.K., Ali, A. \& Khanna, S., 1993. Purification, characterization and cloning of an endo-1,4- $\beta$-glucanase from Ruminococcus sp. Biotechnol. Lett. 13, 907-912.

Sun, H., Yang, J., Lin, C., Huang, X., Xing, R. \& Zhang, K., 2006. Purification and properties of a $\beta$-1,3-glucanase from Chaetomium sp. that is involved in mycoparasitism. Biotechnol. Lett. 28, 131-135.

Vijayendra, S.V.N. \& Kashiwagi, Y., 2008. Characterization of a new acid stable exo- $\beta$-1,3-glucanase of Rhizoctonia solani and its action on microbial polysaccharides. Int. J. Biol. Macromol. 44, 92-97.

Villettaz, J.C., Steiner, D. \& Trogus, H., 1984. The use of $\beta$-glucanase as an enzyme in wine clarification and filtration. Am. J. Enol. Vitic. 35, 253-256.

Wang, J.L., Ruan, H., Zhang, H.F., Zhang, Q., Zhang, H.B., He, G.Q. \& Shen, S.R., 2007. Characterization of a thermostable and acidic-tolerable endo- $\beta$-1,3-glucanase from aerobic fungi Trichoderma koningii ZJU-T. J. Food Sci. 72, C452-456

Zinnai, A., Venturi, F., Quartacci, M.F., Andreotti A. \& Andrich, G., 2010. The kinetic effect of some wine components on the enzymatic hydrolysis of $\beta$-glucan. S. Afr. J. Enol. Vitic. 31, 9-13. 